\title{
Methodological challenges with randomized clinical trials for multifocal intraocular lenses
}

\section{Tuuminen, Raimo}

2020

Tuuminen , R , Kanclerz , P \& Grzybowski , A 2020 , ' Methodological challenges with randomized clinical trials for multifocal intraocular lenses ', Survey of Ophthalmology, vol. 65 , no. 3 , pp. 391-392 . https://doi.org/10.1016/j.survophthal.2019.10.007

http://hdl.handle.net/10138/320978

https://doi.org/10.1016/j.survophthal.2019.10.007

cc_by_nc_nd

acceptedVersion

Downloaded from Helda, University of Helsinki institutional repository.

This is an electronic reprint of the original article.

This reprint may differ from the original in pagination and typographic detail.

Please cite the original version. 


\section{Journal Pre-proof}

Methodological challenges with randomized clinical trials for multifocal intraocular lenses

Raimo Tuuminen, MD, PhD, FEBO, Piotr Kanclerz, MD, PhD, Andrzej Grzybowski, $\mathrm{MD}, \mathrm{PhD}, \mathrm{MBA}$

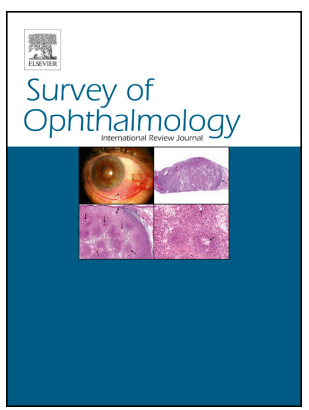

PII:

S0039-6257(19)30286-3

DOI:

https://doi.org/10.1016/j.survophthal.2019.10.007

Reference: SOP 6909

To appear in: Survey of Ophthalmology

Received Date: 11 August 2019

Revised Date: 11 October 2019

Accepted Date: 21 October 2019

Please cite this article as: Tuuminen R, Kanclerz P, Grzybowski A, Methodological challenges with randomized clinical trials for multifocal intraocular lenses, Survey of Ophthalmology (2019), doi: https:// doi.org/10.1016/j.survophthal.2019.10.007.

This is a PDF file of an article that has undergone enhancements after acceptance, such as the addition of a cover page and metadata, and formatting for readability, but it is not yet the definitive version of record. This version will undergo additional copyediting, typesetting and review before it is published in its final form, but we are providing this version to give early visibility of the article. Please note that, during the production process, errors may be discovered which could affect the content, and all legal disclaimers that apply to the journal pertain.

(c) 2019 Elsevier Inc. All rights reserved. 
Raimo Tuuminen, $\mathrm{MD}, \mathrm{PhD}, \mathrm{FEBO}^{1,2}$

Piotr Kanclerz, MD, $\mathrm{PhD}^{3}$

Andrzej Grzybowski, MD, PhD, MBA ${ }^{4,5}$

${ }^{1}$ Helsinki Retina Research Group, Faculty of Medicine, University of Helsinki, Helsinki, Finland

${ }^{2}$ Eye Centre, Kymenlaakso Central Hospital, Kotka, Finland

${ }^{3}$ Hygeia Clinic, Gdańsk, Poland

${ }^{4}$ Department of Ophthalmology, University of Warmia and Mazury, Olsztyn, Poland

${ }^{5}$ Institute for Research in Ophthalmology, Foundation for Ophthalmology Development,

Poznań, Poland

Conflicts of Interest: Dr. Tuuminen reports non-financial support from Thea Laboratoires, personal fees and non-financial support from Bayer, personal fees from Alcon, Allergan and Novartis, outside the submitted work. Dr Kanclerz reports non-financial support from Visim and Optopol Technology, outside the submitted work. Dr. Grzybowski reports non-financial support from Alcon, Bayer and Novartis, personal fees and non-financial support from Santen and Valeant, grants from Zeiss, outside the submitted work. The authors have no proprietary interest within the presented subject.

Corresponding author: Raimo Tuuminen, MD, PhD, FEBO, Chief Physician, Kymenlaakso Central Hospital, Eye Centre, Kotkantie 41, FI-48210 Kotka, Finland. Phone: +358 50411 3870; Fax: +358 92411 227; E-mail: raimo.tuuminen@helsinki.fi 
We have read the article by Cao and coworkers, ${ }^{1}$ and believe that some discussion is required. The authors compared the visual acuity, contrast sensitivity (CS) and adverse events in monofocal intraocular lenses and multifocal IOLs (MIOLs).

The aim of this review was to assess high-quality evidence based on only randomized controlled trials (RCTs). ${ }^{1}$ The risk of bias was assessed in several aspects as recommended by the Cochrane Collaboration; however, some studies included in the final analysis cannot be considered as RCTs; this was meticulously described in the Cochrane review on the same topic. ${ }^{2}$ Four studies included in the meta-analysis by Cao and coworkers ${ }^{1}$ were excluded from the Cochrane review as they were retrospective (Shah and coworkers, 2010), the participants were not randomly allocated to the intervention (Puell and coworkers, 2015, Maxwell and coworkers,2008) or because the Chinese-speaking Cochrane authors confirmed from the trialists that participants were not randomly allocated to the intervention ( $\mathrm{Ji}$ and coworkers,. 2011). ${ }^{2}$ Of note, we believe that it is fairly difficult to perform a RCT in this area of research, as probably every patient would prefer to choose the IOL based on personal preferences, rather than to be randomized between monofocal or MIOL group.

Two out of 21 studies included in the final analysis, and seven out of 61 references were not in English; however, the methods section does not present which languages were included in the search strategy. Although there is no evidence on systemic bias from the use of English-language restrictions in systematic reviews and meta-analyses, ${ }^{3}$ the electronic search strategy of any review article should be repeatable. Moreover, English-language articles more commonly have larger sample sizes, better methodology, present adequate concealment of allocation, and are more commonly double blinded or assessor blinded. ${ }^{3}$

Finally, comparing CS outcomes in MIOLs is difficult due to the variation of tests used, different illumination levels and inconsistency in reported variables. We would like to ask which variables were used for this analysis? It is known that MIOLs might present worse performance in low illuminance conditions and higher spatial frequencies; did this review show similar results? Moreover, it is not stated at which timepoint was CS analyzed, as CS in MIOLs has a tendency to improve over time. Finally, it should be clearly stated that to date none of the studies has presented an association between CS and the quality of vision. ${ }^{4}$

\section{Methods of literature search}

The search strategy was ("Lenses, Intraocular"[Mesh] AND “comparison”[ALL]); ("Multifocal Intraocular Lenses"[Mesh] AND "randomized”[ALL]); (“monofocal Intraocular lenses" AND "randomized”[ALL]); (“Multifocal Intraocular Lenses" [Mesh] AND “randomly”[ALL]); (“monofocal Intraocular lenses” AND “randomly" [ALL]) ("Multifocal Intraocular Lenses”[Mesh] AND "randomization”[ALL]); ("monofocal Intraocular lenses" AND "randomization" [ALL]); ("Intraocular lenses" AND "trial”[ALL]); ("bias" AND ("review” OR “meta-analysis") [ALL]); (“quality of life” AND (“multifocal intraocular lenses") [ALL]) 


\section{References}

1. Cao K, Friedman DS, Jin S, et al. Multifocal versus monofocal intraocular lenses for age-related cataract patients: a system review and meta-analysis based on randomized controlled trials. Surv Ophthalmol. 2019;64(5):647-658.

2. de Silva SR, Evans JR, Kirthi V, Ziaei M, Leyland M. Multifocal versus monofocal intraocular lenses after cataract extraction. Cochrane Database Syst Rev. 2016;12:CD003169.

3. Grzybowski A, Kanclerz P. Language Bias and Methodological Issues in Determining Reliable Evidence for Systematic Reviews. JAMA Ophthalmol. 2019;137(1):118-119.

4. Grzybowski A, Kanclerz P, Muzyka-Woźniak M. Methods for evaluating quality of life and vision in patients undergoing lens refractive surgery. Graefe's Archive for Clinical and Experimental Ophthalmology. 2019;257(6):1091-1099. doi:10.1007/s00417-019-04270-w. 